\title{
Autoimmune destruction of pericytes as the cause of diabetic retinopathy
}

\section{Duncan D Adams}

Faculty of Medicine, University of Otago, Dunedin, New Zealand
Correspondence: Duncan D Adams Faculty of Medicine, University of Otago, PO Box 913, Dunedin 9054, New Zealand Tel +6434558700

Email duncan.adams@stonebow.otago.ac.nz

\begin{abstract}
In diabetic retinopathy, collapse of the retinal vasculature is associated with loss of the pericytes. These are contractile cells that together with endothelial cells form the terminal arterioles of the retina. The cause of the loss of pericytes is not known. Recently, it has been discovered that type 1 diabetes is caused by forbidden clones of cytotoxic T lymphocytes, which destroy the insulin-making cells with exquisite specificity. In the light of this, I postulate that an antigenically-related forbidden clone of cytotoxic $\mathrm{T}$ lymphocytes selectively destroys the pericytes and that this is the cause of the vascular collapse of diabetic retinopathy. If this is so, the therapeutic implications are immense, involving a switch from ineffectual tight glycemic control to immunotherapy. This is already used as immunosuppression to prevent organ transplant rejection, and as the immune ablation and autologous bone marrow cell reconstitution that has saved the lives of patients with lethally-severe scleroderma. Once the pericyte surface auto-antigen for the T lymphocytes has been isolated, selective destruction of the pathogenic $\mathrm{T}$ lymphocytes would be possible by manufacture and use of cytotoxic auto-antigen complexes, which arrests progression of the retinopathy.
\end{abstract}

Keywords: pericytes, diabetic retinopathy, autoimmunity, $\mathrm{T}$ cell forbidden clones, immunotherapy

\section{Etiology of Graves' disease}

The thyroid gland attracted clinical attention because its hormone, thyroxine, as shown by Harington (1933), contains iodine, a trace element. Surprisingly, our dietary supply of iodine, ultimately from soil, does not come from the weathering of rock, but through slow deposition by rainfall of iodine sublimed from the sea (Kelly and Sneddon 1960). Consequently, iodine deficiency occurs in regions with newly formed soils, such as where mountains have been uplifted, as in Switzerland, India, Chile, and New Zealand. The deficiency of iodine in these regions causes goitre, a hypertrophy of the thyroid gland, mediated by thyroid-stimulating hormone from the pituitary gland and preventable by adding iodine to domestic salt. In New Zealand, 1 part of potassium iodide to 20,000 parts of sodium chloride abolished the goitre endemic (Purves 1974).

A second thyroid disease, unrelated to iodine deficiency, was discovered by Graves (1838). There is tachycardia, tremor, weight loss, thyroid enlargement, and exophthalmos. A century later, Adams and Purves (1980) discovered the causative agent, long-acting thyroid stimulator (LATS), which proved to be an autoantibody. Surprisingly, LATS, which was measured by a bioassay in guinea pigs or mice, was present in only about a third of thyrotoxic patients. However, a refinement involving a neutralization step with human thyroid tissue revealed so-called LATS protector, another autoantibody, which correlated with degree of hyperthyroidism, and on infusion was active in stimulating the thyroid glands of several Otago University professors (Adams 1980). This showed that Graves' disease is an autoimmune disease, caused by development of antibodies that accidentally react with a 
host component instead of an invading microbial parasite (Adams and Knight 2003).

\section{Fine variation in thyroid-stimulating autoantibodies}

The thyroid gland's thyrotropin receptor differs slightly in different animals, man, guinea pig, mouse, sheep, or cattle. LATS protector reacts with the human receptor but, unlike LATS, does not cross-react with the thyrotropin receptors of mice or guinea pigs (Adams 1980). The fine variation in the specificity of the thyroid-stimulating autoantibodies, from patient to patient, is explained by Burnet's forbidden clone theory (Burnet 1959), which postulates that autoimmunity arises by unlucky, semi-random, somatic mutations in the $\mathrm{V}$ (immunoglobulin variable region) genes of multiplying lymphocytes.

\section{Eye complications of Graves' disease}

The exophthalmos of Graves' disease has two components. One is a sympathetic nervous system reflex retraction of the eyelids caused by high levels of thyroxine in the blood. The other is an increase in the bulk of the retro-globe tissues, causing protrusion of the globe. Before antithyroid drugs were discovered by Kennedy (1942) in New Zealand and Astwood (1943) in Boston, there was mortality from Graves' disease. This enabled Rundle and Pochin (1964) in London, to make ingenious post-mortem studies that showed the increase in bulk of the orbital tissues to be due to fat, there appearing to be a proliferation of adipose cells throughout the orbit.

\section{Cross-tissue antibody auto-reactivity as the cause of exophthalmos}

Interestingly, LATS, the human autoantibody that cross - reacts with the mouse thyrotropin receptor, correlates better with exophthalmos than with hyperthyroidism (Kriss et al 1967). In malignant exophthalmos, there is hypertrophy of the extra-ocular muscles. It seems that these muscles, in constant fast motion, use high calorific fatty acids for fuel instead of the usual glucose, like the wing muscles of birds, which accounts for the white meat of turkey breasts compared with the dark meat of their legs (Adams 1980). Some variants of the thyroid-stimulating autoantibodies apparently react with receptors on fat cells in the orbit, increasing the amount of fat there and sometimes depriving the extra-ocular muscle cells of fatty acids for their fuel, causing them to hypertrophy (Adams 1980). Pretibial myxoedema on the shins is another extra-thyroidal, cross-tissue manifestation of LATS variants and can be cured by topical application of corticosteroids (Kriss et al 1967).

\section{Etiology of diabetes}

It is now known that there are two distinct forms of diabetes (Sherwin 2000), type 1 and type 2. Type 1 is an autoimmune disease caused by autoimmune destruction of the pancreatic islet beta cells that make insulin. The defect causing type 2 diabetes is unknown. There is resistance to the action of insulin and a very strong genetic causation with near 100\% concordance of identical twins. This compares with the $50 \%$ concordance in type 1 diabetes and other autoimmune diseases where unlucky somatic mutations, with their random element, are necessary in lymphocyte genes for creation of the pathogenic forbidden clones.

A difference between Graves' disease and type 1 diabetes is in the type of lymphocyte mutating into the forbidden clone. Mutations in B lymphocytes give rise to the plasma cells secreting the thyroid-stimulating autoantibodies, whereas there is now clear evidence (Sherwin 2000; Adams and Knight 2003) that forbidden clones of cytotoxic T lymphocytes destroy the pancreatic islet insulin-making cells, with exquisite specificity, leaving the other islet cells untouched. Cheynier and colleagues (1998) at the Pasteur Institute were the first to demonstrate somatic mutation in the $\mathrm{V}$ genes of multiplying $\mathrm{T}$ cells, where it is rarer than in B cells because of the protective suppressor T cell phenomenon (Adams 1983).

\section{Eye complications of diabetes}

The major complication is diabetic retinopathy, in which the vasculature collapses, causing blindness, as described and illustrated by Klintworth (1988).

\section{Loss of pericytes in diabetic retinopathy}

The name pericyte derives from the Greek "kytos", a hollow vessel, aptly describing a cell surrounding a terminal arteriole. Unlike their associated endothelial cells, pericytes have contractile power and can be imagined as the last stage of the progression from arteries with multiple smooth muscle cells in their media to capillaries with no contractile ability.

In diabetic retinopathy, there is a loss of pericytes associated with vascular collapse (Klintworth 1988) as illustrated in Figure 1.

\section{Autoantibodies to pericytes}

These occur in people (Nayac et al 2005) and have a loose association with retinopathy, renal failure and hypertension. 


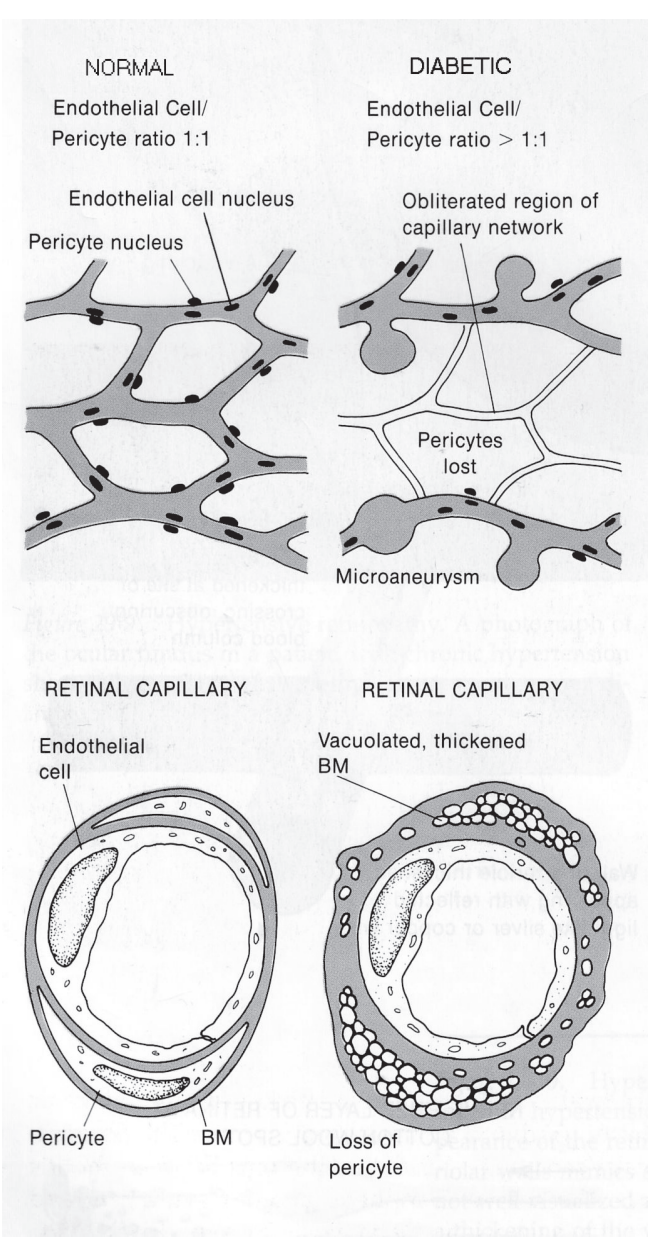

Figure I Diabetic retinopathy, illustrating the loss of pericytes and associated collapse of the vasculature. Copyright () 1988. Reprinted with permission from Klintworth GK. 1988. The eye. In: Rubin E, Farber JL (eds). Pathology. 2nd edn. Philadelphia: Lippincott, pp. I 456-83.

Measured by a fluorescence technique, using cultured bovine retinal cells, they do not show a causative relationship to retinopathy (Nayac et al 2007). They may reflect damage to contractile blood vessels, including the retinal pericytes.

\section{Cross-tissue T cell auto-reactivity as the cause of diabetic retinopathy}

The cause of the loss of pericytes in diabetic retinopathy is not yet known. By analogy with the established cross-tissue B lymphocyte auto-reactivity of Graves' disease, I postulate that cross-tissue $\mathrm{T}$ cell auto-reactivity is responsible. This would be analogous to the situation with the islet cell autoimmunity, where the islet cell autoantibodies, discovered by Doniach and her colleagues (Bottazzo et al 1974) are not the destructive agents, but are passive consequences of the destruction by cytotoxic $\mathrm{T}$ cell forbidden clones.

\section{Therapeutic implications}

The therapeutic implications are immense, involving a switch from tight glycemic control, which does not prevent retinopathy, to immunotherapy by immunosuppression or by elimination of the $\mathrm{T}$ lymphocyte pathogenic forbidden clones. Immunosuppression is already widely familiar, being in use for prevention of rejection of organ transplants. Recently, Englert and her colleagues (2005) saved the lives of three patients with systemic scleroderma of lethal severity. By destroying the patients' immune systems with immuno-suppressive chemotherapy, they got rid of their lethally-dangerous fibroblast-stimulating forbidden clones (Adams and Knight 2003), then restored their immune systems with stem cells previously taken from each patient's own bone marrow. This autologous bone marrow grafting (Applebaum 2005) was necessary to prevent their patients from dying of microbial infections in the absence of their destroyed immunity systems. Because forbidden clones of $\mathrm{B}$ or $\mathrm{T}$ lymphocytes arise by unlucky somatic mutations in their $\mathrm{V}$ genes, during the multiplication of lymphocytes in the periphery (Adams and Knight 2003), they are very unlikely to reappear in the new, regenerated immune system. An alternative method for destroying the immune system would have been the use of total lymphoid irradiation (Fisher et al 2005). This too would have destroyed the forbidden clones of lymphocytes that were causing their patients' life-endangering systemic scleroderma.

For therapy of diabetic retinopathy and nephropathy, immunosuppression needs urgent trial and following this, for severe cases immune ablation and autologous bone marrow cell reconstitution would be appropriate (Adams 2006). Research to isolate the pericyte auto-antigen reactive with $\mathrm{T}$ cells is an urgent necessity and will enable ideal therapy in the form of selective destruction of the pathogenic forbidden clones, by manufacture and use of cytotoxic-autoantigen complexes, with the rest of the immunity system left untouched (Adams and Knight 2003).

\section{Acknowledgment}

I am indebted to Prof. Don Robertson, Pro-Vice-Chancellor for Health Sciences at the University of Otago, for his encouragement and administrative help.

\section{References}

Adams DD. 1980. Thyroid-stimulating autoantibodies. Vitam Horm, 38:119-203.

Adams DD. 1983. Autoimmune mechanisms. In: Davies TF (ed). Autoimmune endocrine disease. New York: Wiley, pp. 1-39.

Adams DD. 2006. Seven deficiencies in Harrison's 16th edition 2005 J Clin Lab Immunol, 54:1-13. 
Adams DD, Knight JG. 2003. Principles of autoimmune diseases: pathogenesis, genetics and specific immunotherapy. J Clin Lab Immunol, 52:1-22.

Applebaum FR. 2005. Hematopoietic cell transplantation. In: Kasper DL, Fauci AS, Longo DL, et al. (eds). Harrison's Principles of Internal Medicine. 16th edn. New York: McGraw-Hill, pp. 668-73.

Astwood EB. 1943. The chemical nature of compounds which inhibit the function of the thyroid gland. J Pharmacol Exper Therap, 78:79-89.

Burnet FM. 1959. Autoimmune disease. BMJ, 2:645-50; 720-5.

Bottazzo GF, Florin-Christensen A, Doniach D. 1974. Islet cell antibodies in diabetes mellitus with autoimmune polyendocrine deficiencies. Lancet, 2:1279-83.

Cheynier R, Henrickwark S. Wain-Hobson S. 1998. Somatic hypermutation in the $\mathrm{T}$ cell receptor $\mathrm{V}$ beta gene in microdissected splenic white pulps from HIV-1-positive patients. European J Immunology, 28:1604-10.

Englert H, Katelaris C, McGill N, et al. 2005. "Grape-sultana" sign represents a favourable response to aggressive treatment of early diffuse systemic scleroderma. Intern Med J, 35:436-7.

Fisher AJ, Rutherford RM, Bozzino J, et al. 2005. The safety and efficacy of total lymphoid irradiation in progressive bronchiolitis obliterans syndrome after lung transplantation. American J Transplant, 5:537-43.

Graves RJ. 1838. Clinical lectures. Philadelphia: Adam Waldie, pp. 134-6.

Harington CR. 1933. The thyroid gland. London: Oxford Univ Pr.

Kelly FC, Snedden WW. 1960. Prevalence and geographic distribution of endemic goitre. Geneva; World Health Organisation.
Kennedy TH. 1942. Thioureas as goitrogenic substances. Nature, 150:233-4.

Kriss JP, Pleshakov V, Rosenblum AL, et al. 1967. Studies on the pathogenesis of the ophthalmopathy of Graves' disease. J Clin Endocrinol Metab, 27:582-93.

Klintworth GK. 1988. The eye. In: Rubin E, Farber JL (eds). Pathology. 2nd edn. Philadelphia: Lippincott, pp. 1456-83.

Nayac RC, Agardh E, Kwok MG, et al. 2005. Albinuria and hypertension are independently associated with circulating antipericyte autoantibodies in type 2 diabetic patients. Metabolism, 54:188-93.

Nayac RC, Lynch K, Gustavsson C, et al. 2007. Circulating antipericyte autoantibodies: a novel modifier of risk of progression of diabetic retinopathy. Retina, 27:211-15.

Purves HD. 1974. The aetiology and prophylaxis of endemic goitre and cretinism. New Zealand Med J, 80:477-9.

Rundle FF. 1964. The eye signs of Graves' disease. In: Pitt-Rivers R, Trotter WR, (eds). The thyroid gland. Vol 2. London: Butterworth, pp. 171-97.

Sherwin RS. 2000. Diabetes mellitus. In: Goldman L, Bennett JC, (eds). Cecil Textbook of Medicine. 21st edn. Philadelphia: Saunders, pp. 1267-8. 